\title{
Comparison of the protective effects of selective endothelin-a receptor antagonist, ambrisentan, and dual endothelin-A/B receptor antagonist, bosentan, in experimental renal ischemia reperfusion injury
}

\author{
Kazimoglu $\mathrm{H}^{1}$, Uysal E2, Dokur $\mathrm{M}^{3}$, Gurer $\mathrm{AO}^{4}$, Batcioglu $\mathrm{K}^{5}$, Uyumlu BA ${ }^{5}$, Petekkaya $\mathrm{E}^{6}$, \\ Karadag $\mathrm{M}^{7}$
}

Department of Urology, SANKO University Faculty of Medicine, Gaziantep, Turkey. hkazimoglu@hotmail.com

\begin{abstract}
AIM: This study aims to compare the protective effects of ambrisentan, a selective endothelin typeA receptor antagonist, and bosentan, a dual endothelin typeA/B receptor antagonist, on experimental renal ischemia reperfusion injury.

METHOD: The study sample consisted of 21 female rats, which were divided into 3 groups: Control,

Ambrisentan and Bosentan. For the ischemia-reperfusion injury model, left-kidney nephrectomy was performed after sacrificing the animals. In the immunohistochemical examination, caspase- 3 was examined, and then the apoptotic index was determined. In the biochemical examination, the activities of malondialdehyde (MDA), superoxide dismutase (SOD), glutathione peroxidase, and the levels of nitrite (NOx), TNF- $\alpha$, and IL-1 $\beta$ were determined.

RESULTS: There were statistically significant differences between the groups in terms of total injury score grade in range of $0-3(p=0.001)$. The glomerular and tubular apoptotic indices were higher in the control group as compared to those of the ambrisentan and bosentan groups $(p=0.001)$. There were no statistically significant differences in terms of SOD, CAT, GPx, MDA, IL-1 $\beta$ and TNF- $\alpha$ measurements among the groups $(p>0.05)$. CONCLUSIONS: In the experimentally created renal ischemia reperfusion model, both ambrisentan and bosentan increased the NOx level, decreased the apoptosis, and protected the kidney from renal ischemia reperfusion injury. However, no significant superiority was found between ambrisentan and bosentan in terms of their protective effects (Tab. 3, Fig. 2, Ref. 31). Text in PDF www.elis.sk KEY WORDS: kidney, ischemia-reperfusion, apoptosis, ambrisentan, bosentan, rat.
\end{abstract}

\begin{abstract}
Abbreviations: RIR - renal ischemia reperfusion, TNF- $\alpha$ - tumor necrosis factor alpha, IL-6 - interleukin 6, ET-1 - dual endothelin-1, ADP - adenosine diphosphate, MDA - malondialdehyde, SOD - superoxide dismutase, CAT - catalase, H-E - hematoxylin and eosin, IR - ischemia-reperfusion, HPFs - high-power fields, HRP - avidin-horseradish peroxidase PBS - buffer saline solution, $\mathrm{Cu}^{2+}$ - copper, $\mathrm{H}_{2} \mathrm{O}_{2-}$ hydrogen peroxide, $\mathrm{GPx}$ - glutathione peroxi-

${ }^{1}$ Department of Urology, SANKO University Faculty of Medicine, Gaziantep, Turkey, ${ }^{2}$ Department of General Surgery, SANKO University Faculty of Medicine, Gaziantep, Turkey, ${ }^{3}$ Department of Emergency Medicine, Biruni University Faculty of Medicine, Istanbul, Turkey, ${ }^{4}$ Department of General Surgery and Transplantation Center, SANKO University Faculty of Medicine, Gaziantep, Turkey, ${ }^{5}$ Department of Biochemistry, Inonu University Faculty of Pharmacy, Malatya, Turkey, ${ }^{6}$ Department of Anatomy, Kastamonu University Faculty of Medicine, Kastamonu, Turkey, and ${ }^{7}$ Department of Biostatistics and Medical Information, Hatay Mustafa Kemal University Faculty of Medicine, Hatay, Turkey.
\end{abstract}

Address for correspondence: $\mathrm{H}$. Kazimoglu, Prof, MD, Department of Urology, SANKO University Medical Faculty, Incilipinar Mah. Ali Fuat Cebesoy Bulv. No: 4527090 Gaziantep, Turkey.

Phone: +90.342.2115000, Fax: +90.342.2115010 dase, GSH - reduced glutathione, GS-SG - oxidized glutathione, NOx - nitric oxide, ELISA - enzyme-linked immunosorbent assay, ANOVA - one-way analysis of variance.

\section{Introduction}

Renal transplantation has been considered as the best treatment for the end-stage renal disease. The number of donors per year does not change significantly although the number of patients in need of transplantation increases steadily. Therefore, the obtained kidney should be protected in the best way, especially against renal ischemia reperfusion (RIR) injury/damage because RIR injury is strongly associated with mortality and morbidity (1).

Ischemia is defined as an insufficiency or blockage of blood supply to an organ or tissue due to various reasons, whereas reperfusion is the restoration of blood flow to an organ or tissue after its blockage. By restoring the blood flow or reperfusion to an ischemic tissue, a release of many agents effective in destructing the tissue causes tissue damage due to reperfusion injury. The severity of the damage varies depending on the duration of ischemia, temperature 


\section{$547-553$}

of the tissue, and tissue-specific factors. Microvascular networks are functional dynamic anatomical units responsible for feeding each tissue to meet its metabolic and functional demands, and removing the arising waste products. Dysfunctional transformation of endothelial cells begins with the structural and functional change in intrarenal microvascular network. These microvascular branches, which have glomerular and peritubular capillaries in the kidney, are effective in the progression of kidney damage by reducing glomerular filtration (2).

In addition, RIR damage causes a delayed graft function and graft loss (3). RIR injury has a very complex pathophysiology, involving the activation of neutrophils, increase in the release of free oxygen radicals, and in particular increase in cytokines such as tumor necrosis factor alpha (TNF- $\alpha$ ) and interleukin 6 (IL-6). Impaired blood flow in renal microcirculation, endothelial dysfunction, peritubular capillary loss, and increased vasoconstriction result in acute renal damage $(4,5)$. Increased TNF- $\alpha$ also activates apoptosis and leads to elevated organ damage (6). For this reason, many agents that used to be applied for treating RIR injury were targeted on specific actions including the correction of renal microcirculation, suppression of inflammatory process, and reduction of apoptosis. Fluvoxamine, milrinone and simvastatin are among these agents and have been shown to reduce RIR damage $(3,7,8)$. Despite the improvements in treatment, the mortality and morbidity rates due to RIR injury remains still high, indicating that new treatment approaches are still needed (9).

Bosentan is a dual endothelin-1 (ET-1) receptor antagonist used in pulmonary arterial hypertension and systemic sclerosis along with having antiapoptotic and antiinflammatory features $(10,11)$. Some studies have suggested that there may be a relationship between ET-1 and RIR injury since plasma ET-1 levels have been reported to be elevated in acute renal failure and ischemia in addition to the increase in ET-1 receptor affinity in renal ischemia $(12,13)$. ET-1 has been also reported to reduce glomerular filtration rate and blood flow (14). In their experimental study, Herrero et al showed that ET-1 contributes to RIR injury (15). Cumulative findings from previous studies indicate that the use of ET-1 receptor antagonist may reduce RIR damage. Therefore, bosentan, which is a dual endothelin-1 receptor antagonist and has antiapoptotic and anti-inflammatory properties, was selected in this study as one of the agents that could be possibly used in the treatment of RIR injury.

Ambrisentan ET-A receptor is a selective non-sulfonamide endothelin receptor antagonist of the propanoic acid class. Several previous studies confirmed that it increases the release of nitric oxide, increases endothelium-dependent vasodilator adenosine diphosphate (ADP), and increases blood flow in the vessels during reperfusion. It also provides gene expression of proinflammatory cytokines such as TNF- $\alpha$ and interleukin-6 (16). Because of these features, ambrisentan may have a protective effect against RIR injury, and has been therefore selected as the second possible agent used in this study. Accordingly, the aim of this study was to compare the possible protective effects of selective endothelin-A receptor antagonist, ambrisentan, and dual endothelin-A/B receptor antagonist, bosentan, on experimental RIR injury.

\section{Materials and methods}

\section{Rat groups}

Twenty-one female Wistar albino rats, weighing between 200 and $250 \mathrm{~g}$, were used in this study. These rats were randomly divided into 3 groups with seven rats per group: Control group (Group 1; n: 7), Ambrisentan group (Group 2; n: 7) and Bosentan group (Group 3; n: 7).

\section{Anesthesia and surgical technique}

The rats were kept at $18{ }^{\circ} \mathrm{C}$ (12-hour day/night cycle) in cages (4 rats in each cage) while allowing them free access to water and food. Standard rat feed and water were provided to them. While no agents were administered to the rats in Group 1 before the procedure, the Group 2 rats were administered with $10 \mathrm{mg} /$ $\mathrm{kg}$ ambrisentan (BSF 208075 ETA-RA) in $2 \mathrm{ml}$ saline intraperitoneally 30 minutes before reperfusion. The Group 3 rats were administered with $10 \mathrm{mg} / \mathrm{kg}$ bosentan (Ro 47-0203 / 001) in $2 \mathrm{ml}$ saline intraperitoneally 30 minutes before reperfusion. All rats were anesthetized with $75 \mathrm{mg} / \mathrm{kg}$ ketamine (Ketalar, Pfizer, USA) and $10 \mathrm{mg} / \mathrm{kg}$ Xylazine (Rompun, Bayer AG, Leverkusen, Germany), intraperitoneally. Following the anesthesia, a 6-cm mid-abdomen incision was performed to see both kidneys and spleen. After opening the abdomen, a warm solution of $10 \mathrm{ml}$ sterile $0.09 \% \mathrm{NaCl}$ was administered intraperitoneally to replace the required fluid. In the ischemia-reperfusion injury model, a microvascular clamp was placed on the left renal pedicle, and the renal blood flow was interrupted for 45 minutes. Then, the microvascular clamp was removed and the blood flow was restored. After observing that the renal color returned to normal, the abdominal incisions of each rat were sutured with continuous stitches using $4 / 0$ polyglactin (vicryl rapide, polyglactin, Ethicon co., USA) suture. Heparin was not given to any of the experimental groups. After 3 hours of reperfusion, the rats were sacrificed by decapitation under anesthesia. After sacrificing the animals, left nephrectomy was performed via the previous 6-cm mid-abdomen incision used to create ischemia reperfusion. The kidney was divided longitudinally into two equal parts. One part of the tissue sample was fixed in an Eppendorf tube, and kept at $-80^{\circ} \mathrm{C}$ for malondialdehyde (MDA), superoxide dismutase (SOD), and catalase (CAT) determinations. The remaining part was fixed in formaldehyde for histopathological examination.

\section{Histopathologic analysis}

The left kidneys of rats were resected fixed in $10 \%$ formalin. Sagittal renal tissue sections were obtained and embedded in paraffin blocks. The sectioned 4- $\mu$ m thick tissue samples of the kidney were mounted on slides. After deparaffinization, each specimen was stained with hematoxylin and eosin (H-E) to examine the level of ischemia-reperfusion (IR) injury.

\section{Histopathological evaluation and grading}

Renal tissue sections obtained from the total of sixteen rats were evaluated microscopically in terms of dilatation of proximal tubules, eosinophilic casts in distal tubules, loss of brush borders, detachment of tubular cells, interstitial edema, whole tubular ne- 
crosis, neutrophil infiltration, and interstitial hemorrhage. The grade of injury or total injury score was described according to injury score (in range of 0 to 3 ) as follows:

0 - no injury in 10 high-power fields (HPFs), x400;

1 - frequency of injured proximal tubules $<20 \%$ in $10 \mathrm{HPFs}$;

2 - frequency of injured proximal tubules between $20 \%$ and $50 \%$ in $10 \mathrm{HPFs}$;

3 - frequency of injured proximal tubules $>50 \%$ in $10 \mathrm{HPFs}$, as well as eosinophilic cast in distal tubules, loss of brush borders, detachment of tubular cells, interstitial edema, whole tubular necrosis, neutrophil infiltration, and interstitial hemorrhage.

All histopathological samples were examined randomly and independently by binocular light microscopes by two experienced pathologists (12).

\section{Immunohistochemical analysis}

\section{Caspase-3 (apoptotic index) evaluation}

As described previously, the localization of caspase-3 was performed in paraffin-embedded kidney tissues by immunohistochemistry using a standard avidin-biotin peroxidase complex technique. A polyclonal rabbit anti-human caspase-3 antibody (Roche mtm laboratories AG, Ventana Medical Systems SA, Molecular Discovery Systems Pty Ltd, USA) recognizing the 32 and $17 \mathrm{kD}$ caspase-3 subunits with no cross reactivity against other caspase family members (manufacturer's specification) were diluted 1:100, and then applied overnight at $4{ }^{\circ} \mathrm{C}$ in a humid atmosphere. Thereafter, the sections were stained by an avidin-biotinylated HRP (peroxidase) procedure using a commercially available kit (ABC Elite, Vector Laboratories, California, USA). AEC was used as a substrate. Finally, the sections were counterstained with hematoxylin. Negative control sections were incubated with normal mouse IgG or normal rabbit serum at the same protein concentration as the primary antibody. Human tonsil tissue is used as a positive control.

The apoptotic index was calculated using the following formula:

Mean number of caspase- 3 positive cells in five random fields $x 100$

Mean number of total cells in five random fields

\section{Biochemical investigations}

The left kidney samples were promptly dissected and perfused with $50 \mathrm{mM}$ (pH: 7.4) of cold phosphate buffer saline solution (PBS). The samples were homogenized in 1/5 (w/V) PBS. The homogenate was sonicated three times for $10 \mathrm{~s}$ with intervals and centrifuged at $20,000 \mathrm{x}$ g for $15 \mathrm{~min}$. Supernatants were separated and kept at $-80{ }^{\circ} \mathrm{C}$ until all biochemical measurements were performed.

\section{Determination of protein levels}

The protein concentrations were determined according to the method of Lowry (Lowry, 1951). This method is based on the reduction of the phosphotungstate complex to molybdenum blue by tyrosine and tryptophan amino acids present in the structures of proteins. The reduction reaction was intensified with copper
$\left(\mathrm{Cu} 2^{+}\right)$. Absorbance was monitored at $650 \mathrm{~nm}$ by a spectrophotometer (UV-1601, Shimadzu Corporation, Kyoto, Japan). Bovine serum albumin was used as the standard.

\section{Determination of malondialdehyde levels}

The malondialdehyde (MDA) levels were determined based on the method of Mihara and Uchiyama (Mihara, 1978). Based on this method, the color change due to the reaction between MDA, which is an end product of lipid peroxidation, and thiobarbituric acid in hot acidic medium was measured spectrophotometrically at $532 \mathrm{~nm}$ with tetramethoxypropane as the standard. The results were expressed as nmol MDA/mg protein.

\section{Determination of superoxide dismutase activity}

The superoxide dismutase (SOD) activity was determined with the method of McCord and Fridovich (McCord, 1969). Based on this method, the activity was measured via SOD-mediated inhibition of cytochrome $\mathrm{c}$ reduction, which is induced by superoxide radicals being produced in the xanthine-xanthine oxidase system. The change in absorbance was monitored for 1 min spectrophotometrically at $550 \mathrm{~nm}$ with bovine $\mathrm{Cu}-\mathrm{Zn}$ SOD as the standard. The results were expressed as U/mg protein.

\section{Determination of catalase activity}

The catalase activity was determined with the method of Luck (Luck, 1963). Briefly, catalase decomposes hydrogen peroxide $\left(\mathrm{H}_{2} \mathrm{O}_{2}\right)$ to water and oxygen $\left(\mathrm{O}_{2}\right)$. The decomposition of $\mathrm{H}_{2} \mathrm{O}_{2}$ was monitored for $1 \mathrm{~min}$ spectrophotometrically at $240 \mathrm{~nm}$. The results were expressed as $\mathrm{U} / \mathrm{mg}$ protein.

\section{Determination of glutathione peroxidase activity}

Glutathione peroxidase (GPx) activity was measured with the method of Lawrence and Burk (Lawrence, 1976). GPx is an enzyme that uses reduced glutathione (GSH) to catalyze the conversion of $\mathrm{H}_{2} \mathrm{O}_{2}$ to water. This reaction also oxidizes the $\mathrm{GSH}$ while $\mathrm{H} 2 \mathrm{O} 2$ is decomposed to $\mathrm{H}_{2} \mathrm{O}$ and $\mathrm{O}_{2}$. The oxidized glutathione (GS-SG) then should be reduced back in order to be used for the decomposition of another $\mathrm{H}_{2} \mathrm{O}_{2}$ molecule to $\mathrm{O}_{2}$ and $\mathrm{H}_{2} \mathrm{O}$. This reduction requires the presence of reduced NADP (NADPH) and glutathione reductase in the medium. In this case NADPH is oxidized to NADP while GS-SG is reduced to GSH. The change in the absorbance was monitored for 3 min spectrophotometrically at $340 \mathrm{~nm}$. The GPx activity was expressed in micromoles of NADPH consumed per minute per milligram of protein (U/mg protein).

\section{Determination of total nitric oxide (NOx) levels}

Nitrites and nitrates are the primary oxidation products of $\mathrm{NO}$ subsequent to the reaction with oxygen. The quantitation of NOx was based on the Griess reaction, in which a chromophore with a strong absorbance at $545 \mathrm{~nm}$ formed by the reaction of nitrite with a mixture of naphthyl ethylenediamine and sulfanilamide (16). The samples were deproteinized with Somogy reagent. The nitrates were reduced to nitrites by copper-coated cadmium in glycine buffer ( $\mathrm{pH}$ 9.7). Total NOx concentrations were calculated by using standard sodium nitrite. Results were expressed as $\mu \mathrm{mol} / \mathrm{mg}$ prt. 


\section{Blood samples collection and analysis}

The anesthetized rats were decapitated and 4-ml blood samples from each rat were collected immediately into the tubes (BD Plymouth, UK) containing EDTA. The tubes were then centrifuged at 2,000 rpm at room temperature for $10 \mathrm{~min}$; the resulting serum was immediately frozen at $-80^{\circ} \mathrm{C}$ for later analysis. The analyses of IL- $1 \beta$ and TNF- $\alpha$ were done at a biochemical laboratory. The serum concentrations of IL- $1 \beta$ and TNF- $\alpha$ were measured using enzyme-linked immunosorbent assay according to the manufacturer's instructions.

\section{Determination of $T N F-\alpha$ levels}

The level of TNF- $\alpha$ in serum was determined by enzyme-linked immunosorbent assay (ELISA) kits obtained from Elabscience Biotechnology Co., Ltd. (Elabscience ELISA Kit Catalog No: E-EL-R0019, USA). These ELISA kits use the sandwich-ELISA principle. The micro ELISA plate provided in this kit has been precoated with an antibody specific to rat TNF- $\alpha$. Standards or samples were added to the micro ELISA plate wells and combined with the specific antibody. Then, a biotinylated detection antibody specific for rat TNF- $\alpha$ and HRP conjugate were added successively to each microplate well and incubated. The absorbance was read at $450 \mathrm{~nm}$ by Biotek Synergy H1 plate reader. The concentrations of Rat TNF- $\alpha$ in the samples were calculated by comparing the OD of the samples to the standard curve. The sensitivity of TNF- $\alpha$ was $46.88 \mathrm{pg} / \mathrm{mL}$.

\section{Determination $I L-1 \beta$ levels}

Similar to TNF- $\alpha$ levels, the level of IL- $1 \beta$ in serum was determined by the same ELISA kits. The micro ELISA plate provided in this kit was pre-coated with an antibody specific to rat IL-1 $\beta$. Standards or samples were added to the micro ELISA plate wells and combined with the specific antibody. Then, a biotinylated detection antibody specific for rat IL-1 $\beta$ and HRP conjugate were added successively to each microplate well and incubated. The absorbance was read at $450 \mathrm{~nm}$ by Biotek Synergy H1 plate reader. The concentration of rat TNF- $\alpha$ in the samples was calculated by comparing the OD of samples to the standard curve. The sensitivity of IL-1 $\beta$ was $18.75 \mathrm{pg} / \mathrm{mL}$.

\section{Statistical analysis}

SPSS (Chicago, IL, United States of America) was used for all statistical analyses. Firstly, the normal distribution of data was tested with the Shapiro-Wilk test. In the comparison of more than two independent groups, one-way analysis of variance (ANOVA) and LSD multiple comparison tests were used for the data with normal distribution while Kruskal-Wallis test was used for the data which were not normally distributed. All pairwise multiple comparison tests were used for pairwise comparisons. Descriptive statistics were reported as mean (standard deviation) for numerical variables, and as numbers and percentages for categorical variables. Level of $\mathrm{p}<0.05$ was considered statistically significant.

\section{Ethical statement}

The protocol was approved by the Animal Ethics Review Committee of KSU, Kahramanmaras, Turkey (Permit number:
2015/03-03). All experiments were conducted in compliance with the relevant international laws and institutional guidelines (Helsinki Declaration).

\section{Results}

\section{Histopathologic assessment}

There were statistically significant differences between the groups in terms of total injury score grade in range of 0-3 (min$\max ; \mathrm{p}=0.001$ ). When comparing the incidence of individual grades in individual groups, the highest incidence scores were grade 2 in the control group (42.9\%) grade 0 in ambrisentan group, and grade 1 in bosentan group. The total injury score was significantly lower in groups 2 and 3 compared to that in group 1 (Tab. 1, Fig. 1A, 1B and 1C).

\section{Immunohistochemical analysis}

There was a significant difference between the groups in terms of both glomerular and tubular apoptotic indices calculated after staining with caspase-3 $(p=0.001)$. The glomerular and tubular apoptotic indices were higher in the control group compared to those in the ambrisentan and bosentan groups (group 1 and group 2, respectively; $\mathrm{p}=0.001$ ) (Tab. 2, Fig. 2A, 2B and 2C).

\section{Biochemical studies}

In the bosentan group, NOx values $(26.24 \pm 3.12 \mathrm{Nmol} / \mathrm{ml})$ were higher than those in the ambrisentan group $(23.15 \pm 2.04$ $\mathrm{Nmol} / \mathrm{ml}$ ). NOx values in the control group were measured as

Tab. 1. Histopathological evaluation and grading after ischemic injury.

\begin{tabular}{|c|c|c|c|c|c|c|}
\hline & & & \multicolumn{3}{|c|}{ Group } & \multirow{2}{*}{ Total } \\
\hline & & & Control & Ambrisentan & Bosentan & \\
\hline \multirow{8}{*}{ Grade } & \multirow{2}{*}{ Grade 0} & $\mathrm{n}$ & 0 & 4 & 1 & 12 \\
\hline & & $\%$ & 0.0 & 57.1 & 14.3 & 42.9 \\
\hline & \multirow{2}{*}{ Grade 1} & $\mathrm{n}$ & 2 & 2 & 3 & 7 \\
\hline & & $\%$ & 28.6 & 28.6 & 42.9 & 25.0 \\
\hline & \multirow{2}{*}{ Grade 2} & $\mathrm{n}$ & 3 & 0 & 3 & 6 \\
\hline & & $\%$ & 42.9 & 0.0 & 42.9 & 21.4 \\
\hline & \multirow{2}{*}{ Grade 3} & $\mathrm{n}$ & 2 & 1 & 0 & 3 \\
\hline & & $\%$ & 28.6 & 14.3 & 0.0 & 10.7 \\
\hline \multirow{2}{*}{ Total } & & $\mathrm{n}$ & 7 & 7 & 7 & 28 \\
\hline & & $\%$ & 100.0 & 100.0 & 100.0 & 100.0 \\
\hline
\end{tabular}

Chi-square Fisher's Exact test result $-20,255: p=0.002$

Tab. 2. Apoptotic index values in renal glomeruli and tubules and interstitium.

\begin{tabular}{lccc}
\hline Groups & $\begin{array}{c}\text { Glomeruli } \\
(\text { mean } \pm \text { SD), range }\end{array}$ & $\begin{array}{c}\text { Tubules } \\
(\text { mean } \pm \text { SD), range }\end{array}$ & $p$ \\
\hline Control $^{\mathrm{c}}$ & $(45.37 \pm 0.56) 1.60$ & $(29.60 \pm 0.42) 1.20$ & $0.001^{*}$ \\
Ambrisentan $^{\mathrm{b}}$ & $(3.17 \pm 0.14) 0.40$ & $(10.00 \pm 0.31) 1.00$ & $0.001^{*}$ \\
Bosentana & $(5.00 \pm 0.23) 0.60$ & $(15.11 \pm 0.20) 0.60$ & $0.001^{*}$ \\
$\mathrm{p}^{* *}$ & $0.001^{+}$ & $0.001^{++}$ & \\
\hline${ }^{*}$ p was obtained from Student t test, ${ }^{* *}$ p was obtained from Mann-Whitney u test, & ${ }^{+}$ \\
p value was obtained from ANOVA test, ${ }^{,+}$p value was obtained from Kruskal-Wallis \\
test. The different abc indices in the column show statistically significant differences \\
between the groups $(\mathrm{p}<0.05)$.
\end{tabular}



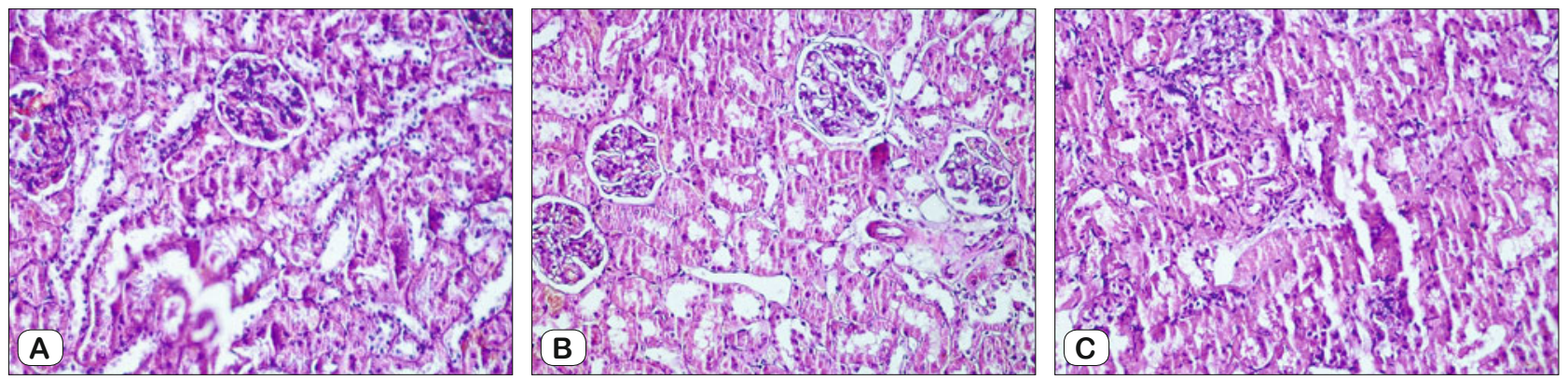

Fig. 1. Glomerular and tubulointerstitial histopathologic changes after renal ischemia-reperfusion injury in rats. (A) Ambrisentan-administered rats group. Almost normal to renal parenchymal tissue in the renal cortex. Edema in proximal tubules, few scattered inflammatory cells. (H\&E staining, original magnification $\mathbf{x} 200$ ). (B) Bosentan-administered rats group. Almost normal to renal parenchymal tissue in the renal cortex. Edema in proximal tubules, few scattered inflammatory cells. (H\&E staining, original magnification, x200). (C) Control group rats. Acute tubular necrosis (ATN) in parenchymal tissue in the renal cortex. Necrosis, inflammatory cells in proximal tubules. (H\&E staining,

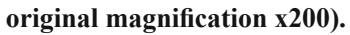
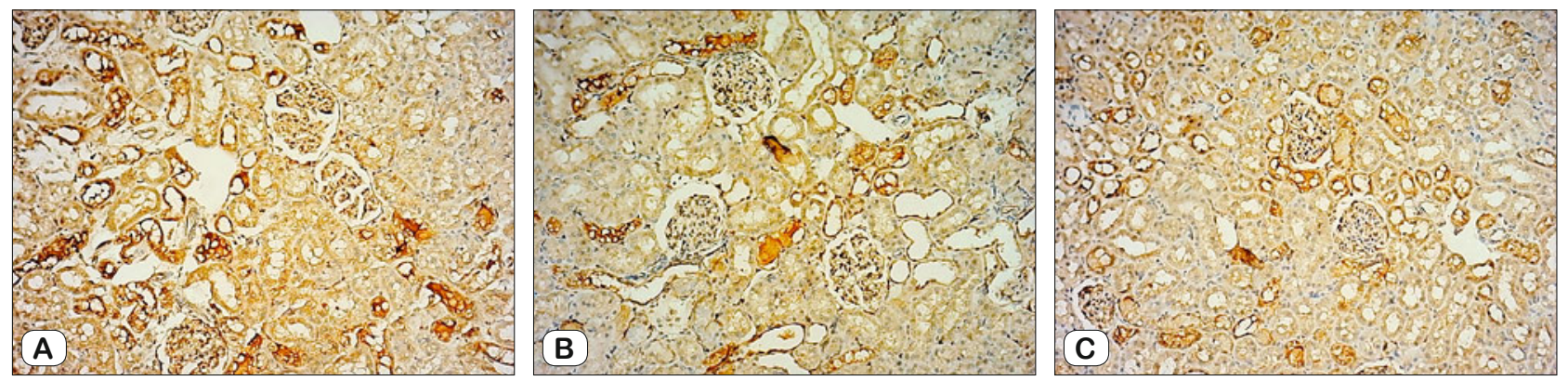

Fig. 2. Glomerular and tubulointerstitial immunochemical changes after renal ischemia-reperfusion injury in rats. (A) Poor staining with caspase-3 in glomeruli is noteworthy in ambrisentan-administered rats group (x400). (B) Moderate or mild staining with caspase-3 in glomeruli and tubules is remarkable in bosentan- administered rats group $(x 400)$. (C) Moderate and strong staining with caspase-3 in glomeruli draws attention in the control group of rats $(\mathbf{x 4 0 0 )}$.

Tab. 3. Biochemical alterations after renal ischemia reperfusion in a rat model.

\begin{tabular}{|c|c|c|c|c|c|}
\hline Parameter Gro & & $\mathrm{N}$ & Mean $( \pm \mathrm{SD})$ & Test Stat. & $\mathrm{p}$ \\
\hline $\begin{array}{l}\text { SOD } \\
\text { (U/mgprt) }\end{array}$ & $\begin{array}{l}\text { Control } \\
\text { Ambrisentan } \\
\text { Bosentan }\end{array}$ & $\begin{array}{l}7 \\
7 \\
7 \\
\end{array}$ & $\begin{array}{l}4.32(1.42) \\
4.76(0.77) \\
5.04(0.84)\end{array}$ & Chi Square $=8.464$ & 0.037 \\
\hline $\begin{array}{l}\text { CAT } \\
\text { (U/mgprt) }\end{array}$ & $\begin{array}{l}\text { Control } \\
\text { Ambrisentan } \\
\text { Bosentan }\end{array}$ & $\begin{array}{l}7 \\
7 \\
7 \\
\end{array}$ & $\begin{array}{l}239.70(107.33) \\
182.60(35.82) \\
180.83(53.87) \\
\end{array}$ & $\mathrm{F}=1.248$ & 0.314 \\
\hline $\begin{array}{l}\text { GPx } \\
\text { (U/mgpr) }\end{array}$ & $\begin{array}{l}\text { Control } \\
\text { Ambrisentan } \\
\text { Bosentan } \\
\end{array}$ & $\begin{array}{l}7 \\
7 \\
7 \\
\end{array}$ & $\begin{array}{l}1.39(0.13) \\
1.85(0.56) \\
1.82(0.51) \\
\end{array}$ & $\mathrm{F}=2.102$ & 0.126 \\
\hline $\begin{array}{l}\text { MDA } \\
\text { (nmol/mgprt) }\end{array}$ & $\begin{array}{l}\text { Control } \\
\text { Ambrisentan } \\
\text { Bosentan }\end{array}$ & $\begin{array}{l}7 \\
7 \\
7 \\
\end{array}$ & $\begin{array}{l}28.82(8.98) \\
28.99(2.64) \\
28.85(6.59) \\
\end{array}$ & $\mathrm{F}=2.736$ & 0.66 \\
\hline $\begin{array}{l}\text { IL-1 } 1 \beta \\
(\mathrm{Pg} / \mathrm{ml})\end{array}$ & $\begin{array}{l}\text { Control } \\
\text { Ambrisentan } \\
\text { Bosentan }\end{array}$ & $\begin{array}{l}7 \\
7 \\
7 \\
\end{array}$ & $\begin{array}{l}88.86(15.43) \\
83.86(17.99) \\
99.57(30.00) \\
\end{array}$ & $\mathrm{F}=2.140$ & 0.122 \\
\hline $\begin{array}{l}\text { TNF- } \alpha \\
(\mathrm{Pg} / \mathrm{ml})\end{array}$ & $\begin{array}{l}\text { Control } \\
\text { Ambrisentan } \\
\text { Bosentan }\end{array}$ & $\begin{array}{l}7 \\
7 \\
7\end{array}$ & $\begin{array}{l}157.59(64.25) \\
130.62(70.13) \\
111.69(48.20)\end{array}$ & Chi-Square $=3.329$ & 0.344 \\
\hline $\begin{array}{l}\mathrm{NOx} \\
(\mathrm{Nmol} / \mathrm{ml})\end{array}$ & $\begin{array}{l}\text { Control }^{\mathrm{c}} \\
\text { Ambrisentan }^{\mathrm{b}} \\
\text { Bosentan }^{\mathrm{a}} \\
\end{array}$ & $\begin{array}{l}7 \\
7 \\
7 \\
\end{array}$ & $\begin{array}{l}20.94(1.66) \\
23.15(2.04) \\
26.24(3.12) \\
\end{array}$ & Chi-Square $=16.549$ & 0.001 \\
\hline
\end{tabular}

* Chi-Square and $\mathrm{F}$ values were obtained from Kruskal-Wallis test and Anova test, respectively. ***abc Within each variable line, the different letters in the superscript show statistical differences between respective groups $(\mathrm{p}<0.05)$.
$18.32 \pm 2.94 \mathrm{Nmol} / \mathrm{ml}$. The differences between the groups in terms of NOx were significant $(\mathrm{p}<0.001)$.

There were no statistically significant differences in terms of SOD, CAT, GPx, MDA, IL- $1 \beta$ and TNF- $\alpha$ measurements among the groups $(p>0.05)($ Tab. 3$)$.

\section{Discussion}

The apoptosis process is defined as a programmed cell death, and includes many different pathways. Apoptosis has been shown as a target in the treatment of many diseases, and it also has a role in ischemia reperfusion injury (16). While ischemia causes apoptosis in the kidney, reperfusion triggers an increase in free oxygen radicals and apoptotic cell death. TNF-alpha is particularly effective in renal injury. Intracellular caspase and apoptosis are also associated with TNF-alpha (6). Caspase also plays a 
critical role in the initiation of apoptosis mechanism while caspase-3 plays an active role in the demolition phase of apoptosis. In our study, we used the apoptotic index to evaluate apoptosis by means of evaluating the caspase- 3 expression. Our results showed that the apoptotic index was the lowest in the ambrisentan group while the highest levels were observed in the control group. The high apoptotic index levels in the control group were significantly higher than those of bosentan and ambrisentan groups, indicating that tissue damage and inflammation are lower in ambrisentan and bosentan groups. Previous studies have shown the efficacy of apoptosis in the reperfusion phase of renal ischemia (17). In addition, the decreased apoptosis in renal ischemia reperfusion injury was previously associated with the decreased TNF- $\alpha$ mRNA level (8). Since apoptosis affects tubular and glomerular cells together in renal ischemia reperfusion injury (18), the apoptotic index in our study was evaluated separately for glomerular and tubular cells. We found that the apoptotic indices were significantly lower in both tubular and glomerular cells in ambrisentan and bosentan groups compared to those in the control group.

During renal ischemia, free oxygen radicals cause cell and tissue death, and have been previously shown to be increasing in the tissue (19). These free oxygen radicals cause lipid peroxidation leading to kidney damage. The protection against free oxygen radicals is through antioxidants, among which SOD, CAT, and GSH-Px are important components of the antioxidant defense system (20). In a normal situation, free oxygen radicals are easily removed via antioxidant enzymes. However, in ischemia and reperfusion, this elimination decreases significantly and free oxygen radicals start to accumulate in the tissue, which results in tissue damage (21).

As shown in previous studies, MDA levels are expected to increase after renal ischemia reperfusion, whereas SOD, CAT and GSH-Px enzyme activities are decreased (22). In their study investigating the effect of lavender oil in RIR, Aboutaleb $\mathrm{N}$ et al showed that SOD, GSH-Px, and CAT activities were increased in the treatment groups whereas their activity was shown to decrease in the untreated sham group (23).

Similarly, Cong G et al (24) as well as Hong X et al demonstrated an increase in SOD, GSH-Px and CAT activity in treatment groups using a polysaccharide from the roots of Dipsacus asperoides (25). Moreover, Gawel S et al (26) reported that luteoline increases SOD and CAT activity in RIR injury, suggesting that luteolin reduces RIR injury and oxidative stress (27). Taking all into consideration, the findings of our study are consistent with previous studies such that SOD and GSH-Px activities are higher in ambrisentan and bosentan groups compared to the control group. The increase in SOD activity is more prominent in the bosentan group. However, there was no statistical significance between the groups. Interestingly, CAT activity in the treatment groups did not increase.

MDA is the final product of polyunsaturated fatty acid peroxidation in the cell, and its production increases when free radicals increase. An increase in MDA indicates oxidative stress and antioxidant status (28). Both Aboutaleb N et al (23) and Hong X et al (25) found elevated MDA levels in untreated ischemia groups. Furthermore, in their study investigating the effect of Juglans mollissin on renal ischemia reperfusion injury, Perez-Meseguer J et al (27) reported that only MDA level in the treatment group is lower compared to that in the ischemia reperfusion group. Similar to previous studies, MDA levels in our study were found to be lower in both abrisentan and bosentan groups as compared to the control group although the differences among the groups did not reach the level of significance. When compared with other previous studies, the observed differences in CAT and MDA values in the treatment groups of our study may be associated with high oxidative stress caused by different ischemic periods and perfusion because Bozlu et al (28) showed that MDA levels could increase significantly four hours after reperfusion. Aboutaleb $\mathrm{N}$ et al (23) reported that different doses of lavender oil cause different levels of MDA. Since different doses of ambrisentan and bosentan were not compared in our study, the relationship between different doses of MDA and treatment groups could not be reported in our study.

Endothelial dysfunction, peritubular capillary loss, increased activation of vasoconstrictor agents, and tubular injuries are among the important processes in the progression of ischemia reperfusion injury. Decreased nitric oxide and impaired NO response contribute to all these processes. Therefore, an increased nitric oxide production and response would likely contribute to the reduction of ischemia-reperfusion injury. In their study of renal ischemia reperfusion injury, Hosszu A et al used fluvoxamine, ol-receptor agonist, and reported that fluvoxamine increases nitric oxide production $(1,3)$. In a similar manner, Ragy MM et al showed that oxytocin and nitro-1-arginine methyl ester administration increases nitric oxide levels and reduces damage in rats with hepatic and RIR injury (29). In line with these results, the nitric oxide levels in our study increased in ambrisentan and bosentan groups as compared to that in the control group. The increase in levels of nitric oxide after using these agents suggests that these agents may play a role in protection against RIR injury.

The role of the inflammatory process in RIR injury has been known for some time. Moreover, a suppression of the inflammatory process and inhibition of inflammatory mediators are critical in reducing RIR injury. Previous studies showed that the agents reducing TNF- $\alpha$ and IL- $1 \beta$ levels also reduce RIR injury $(1,30,31)$. In our study, TNF- $\alpha$, and IL- $1 \beta$ levels are also found to be lower in bosentan and ambrisentan groups than in the control group while this decrease is more prominent in the ambrisentan group. However, there was no statistical significance among the groups, indicating that ambrisentan and bosentan reduce inflammatory mediators. Nevertheless, the absence of statistically significant differences may be related to the dosages and sampling times of the agents.

This study is also not without limitations. Importantly, it does not investigate different dosages of ambrisentan and bosentan against RIR injury. Therefore, there is still a need for future studies on the effects of different dosages of these agents on RIR injury. In addition, the effectiveness of different ischemia and reperfusion times still remains to be elucidated in the future studies. In order to reveal the apparent differences between the groups, detailed ultra-structural examinations and gene and electron microscopy studies should be used in the future studies. 


\section{Conclusion}

Our cumulative results showed that ambrisentan and bosentan increase nitric oxide levels, and decrease apoptosis in an experimental ischemia reperfusion model. With these effects, the reduction in the risk of reperfusion injury following RIR was shown histopathologically by means of lower total injury scores. Although ambrisentan and bosentan decrease also TNF- $\alpha$ and IL-1 $\beta$ levels, these effects are not very prominent with current dosages. Our overall findings suggest that ambrisentan and bosentan both protect the kidney against RIR injury while they are not superior to each other in terms of their protective effect.

\section{References}

1. Gholampour H, Moezi L, Shafaroodi H. Aripiprazole prevents renal ischemia/reperfusion injury in rats, probably through nitric oxide involvement. Eur J Pharmacol 2017; 813: 17-23.

2. Chade AR. Small vessels, big role: renal microcirculation and progression of renal injury. Hypertension 2017; 69 (4): 551-563.

3. Hosszu A, Antal Z, Lenart L, Hodrea J, Koszegi S, Balogh DB et al. $\sigma 1$-Receptor Agonism Protects against Renal Ischemia-Reperfusion Injury. J Am Soc Nephrol 2017; 28 (1): 152-165.

4. Malek M, Nematbakhsh M. Renal ischemia/reperfusion injury; from pathophysiology to treatment. J Renal Inj Prev 2015; 4 (2): 20-27.

5. Nishikido M, Noguchi M, Koga S, Kanetake H, Matsuya F, Hayashi $\mathbf{M}$ et al. Kidney transplantation from non-heart-beating donors: analysis of organ procurement and outcome. Transplant Proc 2004; 36 (7): 1888-1890.

6. Donnahoo KK, Shames BD, Harken AH, Meldrum DR. Review article: the role of tumor necrosis factor in renal ischemia reperfusion injury. J Urol. 1999; 162 (1): 196-203.

7. Zhang Y, Rong S, Feng Y, Zhao L, Hong J, Wang R et al. Simvastatin attenuates renal ischemia/reperfusion injury from oxidative stress via targeting Nrf2/HO-1 pathway. Exp Ther Med 2017; 14 (5): 4460-4466

8. Nishiki T, Kitada H, Okabe Y, Miura Y, Kurihara K, Kawanami S et al. Effect of milrinone on ischemia-reperfusion injury in the rat kidney. Transplant Proc 2011; 43 (5): 1489-1494.

9. Himmelfarb J, Ikizler TA. Acute kidney injury:changing lexicography,definitions, and epidemiology.Kidney Int 2007; 71 (10): 971976

10. Serafim KG, Navarro SA, Zarpelon AC, Pinho-Ribeiro FA, Fattori V, Cunha TM et al. Bosentan, a mixed endothelin receptor antagonist, inhibits superoxide anion-induced pain and inflammation in mice. Naunyn Schmiedebergs Arch Pharmacol 2015; 388 (11): 1211-1221.

11. Gong S, Peng L, Yan B, Dong $Q$, Seng Z, Wang $W$ et al. Bosentan reduces neuronal apoptosis following spinal cord ischemic reperfusion injury. Spinal Cord 2014; 52 (3): 181-185.

12. Mino N, Kobayashi M, Nakajima A, Amano H, Shimamoto K, Ishikawa K et al. Protective effect of a selective endothelin receptor antagonist, BQ-123, in ischemic acute renal failure in rats. Eur J Pharmacol 1992; 221 (1): 77-83.

13. Nambi P, Pullen M, Jugus M, Gellai M. Rat kidney endothelin receptors in ischemia-induced acute renal failure. J Pharmacol Exp Ther 1993; 264 (1): 345-348.

14. Vuurmans JL, Boer P, Koomans HA. Effects of endothelin-1 and endothelin-1-receptor blockade on renal function in humans. Nephrol Dial Transplant 2004; 19 (11): 2742-2746.
15. Herrero I, Torras J, Riera M, Condom E, Coll O, Cruzado JM et al. Prevention of cold ischaemia-reperfusion injury by an endothelin receptor antagonist in experimental renal transplantation. Nephrol Dial Transplant 1999; 14 (4): 872-880.

16. Uhlmann D, Gaebel G, Teupser D, Armann B, Tannapfel A, Ludwig $\mathbf{S}$ et al. Changes of vasoregulatory gene expression following hepatic ischemia/reperfusion and treatment with endothelin-A receptor blockade. J Cardiovasc Pharmacol 2004; 44 Suppl 1: S100-102.

17. Schumer M, Colombel MC, Sawczuk IS, Gobé G, Connor J, O'Toole KM et al. Morphologic, biochemical, and molecular evidence of apoptosis during the reperfusion phase after brief periods of renal ischemia. Am J Pathol 1992; 140 (4): 831-838.

18. Xie J, Guo Q. Apoptosis antagonizing transcription factor protects renal tubule cells against oxidative damage and apoptosis induced by ischemiareperfusion. J Am Soc Nephrol 2006; 17 (12): 3336-3346.

19. Bath NM, Fahl WE, Redfield RR. Significant Reduction of Murine Renal Ischemia-Reperfusion Cell Death Using the Immediate-Acting PrC-210 Reactive Oxygen Species Scavenger. Transplant Direct 2019; 5 (7): e469.

20. Kataoka T. Study of antioxidative effects and anti-inflammatory effects in mice due to low-dose X-irradiation or radon inhalation J Radiat Res 2013; 54 (4): 587-596.

21. Qiu X, Fu K, Zhao X, Zhang Y, Yuan Y, Zhang S et al. Protective effects of astaxanthin against ischemia/reperfusion induced renal injury in mice. J Transl Med 2015; 13: 28.

22. Li Y, Hou D, Chen X, Zhu J, Zhang R, Sun $\mathbf{W}$ et al. Hydralazine protects against renal ischemia-reperfusion injury in rats. Eur J Pharmacol 2019; 843: 199-209.

23. Aboutaleb N, Jamali H, Abolhasani M, Pazoki Toroudi H. Lavender oil (Lavandula angustifolia) attenuates renal ischemia/reperfusion injury in rats through suppression of inflammation, oxidative stress and apoptosis. Biomed Pharmacother 2019; 110: 9-19.

24. Cong G, Cui L, Zang M, Hao L. Attenuation of renal ischemia/reperfusion injury by a polysaccharide from the roots of Dipsacus asperoides. Int J Biol Macromol 2013; 56: 14-19.

25. Hong X, Zhao X, Wang G, Zhang Z, Pei H, Liu Z. Luteolin Treatment Protects against Renal Ischemia-Reperfusion Injury in Rats. Mediators Inflamm 2017; 2017: 9783893.

26. Gawel S, Wardas M, Niedworok E, Wardas P. Malondialdehyde (MDA) as a lipid peroxidation marker. Wiad Lek 2004; 57 (9-10): 453-455.

27. Perez-Meseguer J, Torres-González L, Gutiérrez-González JA, Alarcón-Galván G, Zapata-Chavira H, Waksman-de Torres $\mathbf{N}$ et al. Antiinflammatory and nephroprotective activity of Juglans mollis against renal ischemia-reperfusion damage in a Wistar rat model. BMC Complement Altern Med 2019; 19 (1): 186.

28. Bozlu M, Coskun B, Cayan S et al. Inhibition of poly (adenosine diphosphata-ribose) polymerase decreases long-term histologic damage intesticular ischemia reperfusion injury. Urology 2004; 63 (4): 791-795.

29. Ragy MM, Aziz NM. Prevention of renal ischemia/perfusion-induced renal and hepatic injury in adult male Albino rats by oxytocin: role of nitric oxide. J Basic Clin Physiol Pharmacol 2017; 28 (6): 615-621.

30. Prieto-Moure B, Lloris-Carsí JM, Belda-Antolí M, Toledo-Pereyra LH, Cejalvo-Lapeña D. Allopurinol Protective Effect of Renal Ischemia by Downregulating TNF- $\alpha$, IL-1 $\beta$, and IL-6 Response. J Invest Surg 2017; 30 (3): $143-151$

31. Ozturk H, Cetinkaya A, Yilmaz F, Ozturk H. Protective effect of oxymatrine against renal ischemia/reperfusion injury in rats. Bratisl Lek Listy 2017; 118 (4): 217-222.

Received March 10, 2020. Accepted April 6, 2020. 